\title{
PEMODELAN OPTIMALISASI PRODUKSI \\ UNTUK MEMAKSIMALKAN KEUNTUNGAN \\ DENGAN MENGGUNAKAN METODE PEMROGRAMAN LINIER
}

\author{
Tantri Windarti \\ Program Studi Sistem Informasi \\ STMIK Surabaya \\ Jl. Raya Kedung Baruk 98, Surabaya 60298 \\ tantri@stikom.edu
}

\begin{abstract}
ABSTRAK
PT. X merupakan perusahaan yang memproduksi besi beton dengan berbagai macam ukuran diameter, mulai diameter $6 \mathrm{~mm}$ sampai dengan $32 \mathrm{~mm}$. Dalam memenuhi permintaan produk yang cukup bervariasi membuat perusahaan kesulitan dalam merencanakan produksi untuk menghasilkan keuntungan yang paling maksimal pada periode 1 minggu. Sejauh ini PT. X hanya menentukan jumlah pembuatan produk secara coba-coba dalam memenuhi permintaan, sehingga tidak bisa menghasilkan keuntungan yang maksimal. Untuk membantu memecahkan masalah tersebut digunakan metode pemrograman linier, yaitu suatu cara perencanaan aktivitas yang menggunakan model matematis untuk melakukan perhitungan optimasi produksi dengan tujuan menghasilkan keuntungan maksimal. Dengan metode ini maka diharapkan PT. $X$ dapat menyusun rencana produksi yang lebih optimal dengan memperhatikan keterbatasan sumber daya yang ada. Hasil dari penerapan metode yang digunakan terlihat bahwa dengan menggunakan metode pemrograman linier perusahaan bisa memproduksi besi beton untuk semua diameter sesuai dengan permintaan, sehingga perusahaan selama seminggu memperoleh keuntungan maksimal 23,14\% lebih besar dari keuntungan yang diperoleh sebelumnya.
\end{abstract}

Kata Kunci : Pemodelan, Pemaksimalan Keuntungan, Pemrograman Linier.

\section{PENDAHULUAN}

Setiap perusahaan bertujuan untuk mencari keuntungan yang maksimal dalam menjalankan kegiatan perusahaan. Terlebih pada era globalisasi saat ini, setiap organisasi dituntut senantiasa mamanfaatkan sumber daya yang dimiliki seoptimal mungkin. Namun kenyataannya, perusahaan mengalami banyak hambatan dalam pencapaian tujuan, sehingga perusahaan tersebut mengerahkan berbagai usaha untuk mengatasai masalah yang sedang dihadapinya. Persoalan umum yang dihadapi oleh perusahaan adalah bagaimana mengkombinasikan faktor-faktor produksi atau sumber daya yang dimiliki secara bersama dengan tepat agar diperoleh keuntungan maksimal dengan biaya yang minimal.

Dalam dunia industri, perbandingan antara biaya produksi dengan harga jual sangat mempengaruhi daya saing di pasar. Biaya produksi sangat ditentukan oleh efisiensi dan perhitungan perbandingan input terhadap output dalam proses produksi. Efisiensi merupakan tindakan memaksimalkan hasil dengan menggunakan modal (tenaga kerja, material dan alat) yang minima ${ }^{[1]}$. Efisiensi juga dapat diartikan sebagai upaya penggunaan input yang sekecilkecilnya untuk mendapatkan produksi yang sebesar-besarnya ${ }^{[2]}$. Dengan demikian, pihak manajemen dapat mengkombinasikan faktor-faktor produksi dengan teknik pengelolaan tertentu sehingga dapat menghasilkan suatu produk secara efektif dan efisien dalam jumlah, kualitas, waktu maupun biaya produksinya.

PT. X merupakan salah satu perusahaan manufaktur yang bergerak dalam bidang pengecoran besi. Bahan baku utamanya adalah iron scrap yang dijadikan steel billet (besi batangan) sebagai bahan setengah jadi. Produk yang dihasilkan adalah besi beton dengan berbagai macam diameter, yaitu mulai diameter $6 \mathrm{~mm}$ sampai $32 \mathrm{~mm}$. Diameter yang sangat bervariasi tersebut mengakibatkan harga jual yang berbeda, sehingga keuntungan yang diperoleh juga berbeda. 
Dalam memenuhi permintaan produk yang cukup bervariasi, PT. X telah menetapkan kebijakan bahwa permintaan yang dikerjakan adalah permintaan yang dikumpulkan 1 minggu sebelumnya. Sehingga perusahaan tersebut kesulitan dalam merencanakan produksi untuk menghasilkan keuntungan yang paling maksimal pada periode 1 minggu. Sejauh ini PT. X hanya menentukan jumlah produksi secara coba-coba sehingga tidak bisa menghasilkan keuntungan yang maksimal.

Setiap perusahaan umumnya ingin memperoleh keuntungan maksimal dengan mengoptimalkan keterbatasan sumber daya yang ada ${ }^{[3]}$. Hal itu dapat diselesaikan menggunakan metode pemrograman linier ${ }^{[4]}$. Metode tersebut terbukti dapat mengoptimalkan tujuan produksi yang ingin dicapai berdasarkan batasan-batasan sumber daya yang $\operatorname{ada}^{[5]}$. Hal tersebut dipertegas oleh ilmuwan lain yang menyatakan bahwa bila perusahaan menghasilkan produk yang bervariasi, maka metode perencanaan untuk memproduksi barang agar memperoleh keuntungan yang maksimal dapat diperoleh dengan pemrograman linier ${ }^{[6]}$. Dengan demikian, metode pemrograman linier adalah suatu metode yang digunakan oleh perusahaan dalam memproduksi barang lebih dari satu variasi dengan sumber daya yang terbatas.

Selama ini penentuan perencanaan produksi PT. X belum pernah ditentukan dengan metode pemrograman linier. Karena itu, untuk mengoptimalkan rencana produksi selama 1 minggu di PT. X digunakan model matematis seperti pemrograman linier. Dengan menggunakan metode pemrograman linier yang dibantu software Lingo, maka diharapkan PT. X dapat menyusun rencana produksi yang lebih optimal.

\section{LANDASAN TEORI}

\section{A. Kajian Pustaka}

Penelitian mengenai pemrograman linier telah dilakukan sebelumnya melalui penelitian:

1. Andrie (2012). Dalam penelitian ini, pemrograman linier digunakan untuk memperoleh keuntungan maksimal dengan menentukan kombinasi jumlah produk yang tepat pada CV. Makmur Berseri. Perusahaan ini merupakan pabrik industri kayu yang mengolah bahan baku kayu menjadi barang jadi berupa berbagai macam mebel atau perabotan rumah. Dalam proses produksi, perusahaan mengalamai kesulitan untuk menentukan jumlah produksi yang optimal sesuai dengan ketersediaan sumber daya yang dimiliki oleh perusahaan, seperti bahan baku dan jam kerja tenaga kerja. Selain itu, adanya fluktuasi permintaan masing-masing jenis produk tiap bulannya turut menjadi penyebab sulitnya perusahaan dalam menentukan jumlah produksi yang optimal. Dengan menggunakan pemrograman linier diperoleh jumlah produksi masing-masing produk yang optimal, yaitu kursi baso $=1.124$ buah, kursi lipat $=$ 1.073 buah, rak dispenser $=1.245$ buah, rak TV $=729$ buah dan ranjang tunggal $=448$ buah. Keuntungan maksimal yang diperoleh perusahaan berdasarkan kombinasi produk tersebut sebesar Rp. 176.332.569, $-^{[7]}$

2. Pratama (2012). Dalam penelitian ini, pemrograman linier digunakan untuk menghasilkan kombinasi beberapa produk berdasarkan keterbatasan sumber daya pada industri sambal sehingga diperoleh keuntungan yang maksimal. Semua jenis produk perusahaan ini menggunakan bahan baku yang sama dalam proses produksinya. Industri sambal ini belum menerapkan penggunaan sumber daya yang optimal. Hal itu dapat dilihat dari sering terjadinya penumpukan hasil produksi di gudang penyimpanan. Selain itu, adanya ketidakmampuan industri sambal dalam menentukan jumlah produksi yang optimal. Sehingga mengakibatkan industri sambal mengalami kekurangan dan kelebihan produksi yang dapat menyebabkan keuntungan yang diperoleh tidak maksimal. Dengan menggunakan pemrograman linier, industri sambal memperoleh keuntungan maksimal sebesar Rp. 234.347.800,- dengan kombinasi produk sambal yang harus diproduksi sebanyak 45.835 unit sachet, produk botol kecil $140 \mathrm{ml}$ sebanyak 54.675 unit, produk botol sedang $320 \mathrm{ml}$ sebanyak 59.418 unit, 
produk botol besar $600 \mathrm{ml}$ sebanyak 7.684 unit, produk jerigen $5 \mathrm{~kg}$ sebanyak 603 unit, dan produk botol sedang seafood $320 \mathrm{ml}$ sebanyak 5.791 unit. Setelah dilakukan optimasi menggunakan pemrograman linier, peningkatan persentase keuntungan yang diperoleh perusahaan ini sebesar $12,34 \%$ setiap tahunnya, dimana sebelumnya hanya diperoleh rata-rata sebesar 7\%, sehingga selisih peningkatan keuntungan yang diperoleh mencapai 5,34\% ${ }^{[3]}$.

\section{B. Pemrograman Linier}

Pemrograman linier merupakan proses optimasi dengan menggunakan model keputusan yang dapat diformulasikan secara matematis dan timbul karena adanya keterbatasan dalam mengalokasikan sumber daya. Semua persoalan pemrograman linier mempunyai empat sifat umum sebagai berikut ${ }^{[8]}$ :

1. Persoalan pemrograman linier bertujuan untuk memaksimalkan atau meminimalkan pada umumnya berupa laba atau biaya sebagai hasil yang optimal. Sifat umum ini disebut sebagai fungsi utama (objective function) dari suatu pemrograman linier.

2. Adanya kendala atau batasan (constraints) yang membatasi tingkat sampai dimana sasaran dapat dicapai. Oleh karena itu, untuk memaksimalkan atau meminimalkan suatu kuantitas fungsi tujuan bergantung kepada sumber daya yang jumlahnya terbatas.

3. Harus ada alternatif tindakan yang dapat diambil. Hal ini berarti jika tidak ada alternatif yang dapat diambil, maka pemrograman linier tidak diperlukan.

4. Tujuan dan batasan dalam permasalahan pemrograman linier harus dinyatakan dalam hubungan dengan pertidaksamaan atau persamaan linear.

Langkah-langkah untuk membuat model pemrograman linier adalah sebagai berikut ${ }^{[9]}$ :

1. Menentukan variabel-variabel dari persoalan, misalnya x1, x2 dan seterusnya.

2. Menentukan tujuan (maksimasi atau minimasi) yang harus dicapai untuk menentukan pemecahan optimum dari semua nilai yang layak dari variabel tersebut.

$$
\mathrm{Z}=\sum_{j=1}^{n} c_{j} X_{j}
$$

3. Menentukan batasan-batasan yang harus dikenakan untuk memenuhi batasan sistem yang dimodelkan.

$$
\begin{gathered}
\sum_{j=1}^{n} a_{i j} X_{j} \leq(\geq ;=) b_{i}, \quad(i=1,2, \ldots, m) \\
X_{j} \geq 0, \quad(j=1,2, \ldots, n)
\end{gathered}
$$

dimana:

$\mathrm{Z}$ : nilai fungsi tujuan

$X_{j}$ : banyaknya kegiatan $j(j=1,2, \ldots, n)$

$c_{j}$ : sumber per-unit kegiatan, untuk masalah memaksimalkan $c_{j}$ menunjukkan keuntungan per-unit perkegiatan, sedangkan untuk kasus meminimalkan $C_{j}$ menunjukkan biaya per-unit perkegiatan.

$b_{i}$ : besarnya sumber daya $i(i=1,2, \ldots, m)$

$a_{i j}$ : banyaknya sumber daya $i$ yang dipakai sumber daya $j$.

\section{METODOLOGI PENELITIAN}

\section{A. Metode Pengumpulan Data}

1. Studi Lapangan

Yaitu suatu pengumpulan data dengan melakukan suatu penelitian secara langsung pada perusahaan, adapun cara yang dilakukan yaitu melalui pengamatan, wawancara dan dokumen perusahaan. Sedangkan data yang diperlukan untuk penelitian ini 
adalah harga jual besi beton, biaya pembuatan steel billet, biaya energi, biaya kelebihan dan kekurangan produk, biaya penggantian roll, dan permintaan perminggu.

2. Studi Pustaka

Peneliti memperoleh referensi yang dibutuhkan dengan cara membaca buku-buku dan jurnal-jurnal yang berkaitan dengan topik dan masalah yang dihadapi untuk memecahkan masalah dalam penelitian ini. Selain itu juga sebagai data penunjang kelengkapan informasi yang digunakan untuk melengkapi landasan teori.

\section{B. Pengolahan Data}

Pengolahan data dilakukan berdasarkan literatur yang digunakan dengan asumsiasumsi yang telah ditetapkan serta dilakukan dengan bantuan software Lingo. Sebelum melakukan pengolahan data lebih lanjut, berikut ini adalah gambaran secara umum tentang alur steel billet yang diproses menjadi besi beton.

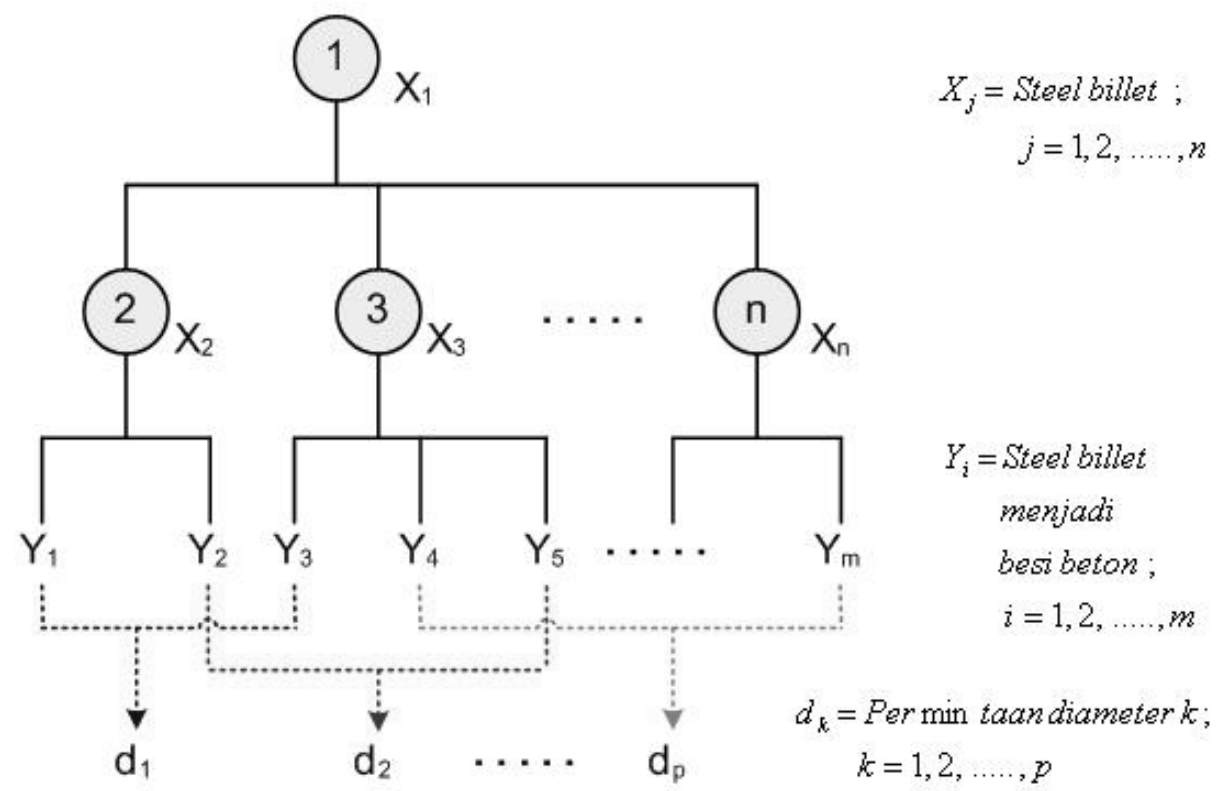

Gambar 1. Alur Umum Steel Billet yang diproses menjadi Besi Beton berikut:

Langkah-langkah yang dilakukan untuk melakukan pengolahan data adalah sebagai

\section{Variabel Keputusan}

Variabel keputusan, merupakan variabel persoalan yang akan mempengaruhi nilai tujuan yang hendak dicapai. Pada penelitian ini variabel keputusannya adalah:

$\mathrm{Y}_{\mathrm{i}}$ : jumlah steel billet yang diproses menjadi produk jadi (besi beton) dengan diameter $\mathrm{k}$ (steel billet/minggu).

\section{Fungsi Tujuan}

Model matematis untuk merumuskan masalah proses produksi steel billet di PT. $\mathrm{X}$ guna mendapatkan keuntungan maksimal dapat dituliskan sebagai berikut:

$$
\operatorname{Max} \mathrm{Z}=\sum_{i=1}^{m} \mu_{i} Y_{i}-\sum_{k=1}^{p}\left(\rho_{k} M_{k}+\lambda_{k} L_{k}\right)-\sum_{j=1}^{n} \psi_{j} R_{j}
$$


Keterangan:

$\mu_{\mathrm{i}}$ :keuntungan yang diperoleh pada penjualan besi beton diameter i (rupiah/steel billet).

$\mathrm{Y}_{\mathrm{i}}$ :jumlah steel billet yang diproses menjadi produk jadi (besi beton) dengan diameter $\mathrm{k}$ (steel billet/minggu). Untuk besi beton dengan diameter tertentu, permintaan bisa dipenuhi dari lebih satu $\mathrm{Y}_{\mathrm{i}}$. Misalkan besi beton diameter 12 bisa dipenuhi dari $\mathrm{Y}_{1}, \mathrm{Y}_{4}$ dan $\mathrm{Y}_{6}$.

$\rho_{\mathrm{k}}$ :biaya kekurangan produk diameter $\mathrm{k}$ (rupiah/ton).

$\lambda_{\mathrm{k}}$ :biaya kelebihan produk diameter k (rupiah/ton).

$\psi_{\mathrm{j}}$ :biaya menyiapkan roll j (rupiah/minggu).

$\mathrm{M}_{\mathrm{k}}$ : kekurangan produk besi beton diameter $\mathrm{k}$ (ton/minggu).

$\mathrm{L}_{\mathrm{k}}$ : kelebihan produk besi beton diameter $\mathrm{k}$ (ton/minggu).

$\mathrm{R}_{\mathrm{j}}$ : bilangan biner, berharga 1 apabila roll digunakan dan 0 apabila tidak digunakan.

\section{Fungsi Pembatas}

Batasan-batasan teknis yang membatasi fungsi tujuan pada penelitian ini antara lain sebagai berikut:

\section{a. Batasan Input-Output}

Jumlah steel billet yang dihasilkan (output) tidak boleh melebihi jumlah steel billet yang keluar (input).

$$
\sum X_{\text {output }} \leq X_{\text {input }}
$$

Sebagai contoh, jumlah steel billet yang keluar dari roll 2, roll 3 dan roll 89 tidak boleh lebih dari jumlah steel billet yang keluar dari roll 1. Sehingga dapat dituliskan:

$$
\mathrm{X}_{2}+\mathrm{X}_{3}+\mathrm{X}_{89} \leq \mathrm{X}_{1}
$$

Untuk lebih jelasnya dapat dilihat dalam lingkaran merah pada Gambar 2.

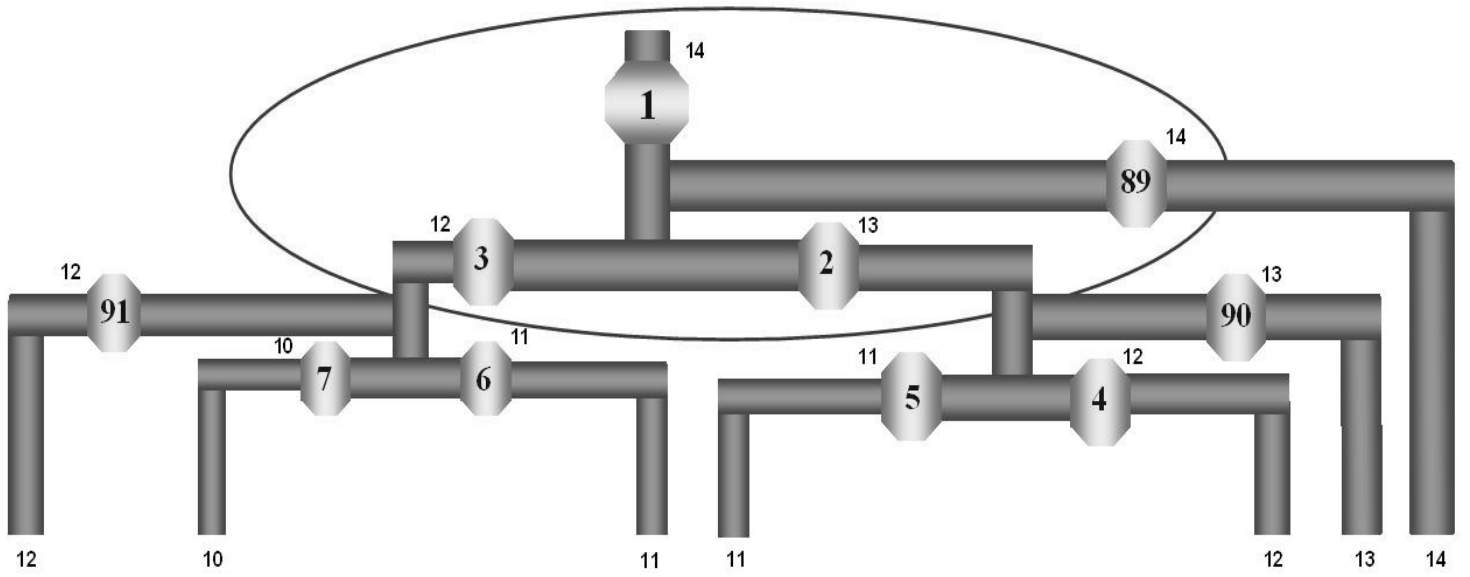

Gambar 2. Alur Input-Output 
Dari gambar di atas didapatkan pemodelan sebagai berikut:

$$
\sum_{j \in J} X_{j} \leq X_{t} \quad, \quad \mathrm{t} \in \mathrm{J} \neq \mathrm{j}
$$

\section{b. Batasan Waktu}

Untuk memproduksi steel billet menjadi besi beton memerlukan batasan waktu, yaitu waktu pemrosesan steel billet melalui roll dan waktu yang dibutuhkan untuk menyiapkan roll. Pemodelan sebagai berikut:

$$
\sum_{j=1}^{n}\left(\xi_{j} X_{j}+\pi_{j} R_{j}\right) \leq T
$$

Keterangan:

$\xi_{\mathrm{j}}$ : waktu yang diperlukan untuk memproses steel billet melalui roll $\mathrm{j}$.

$\pi \mathrm{j}$ : waktu yang diperlukan untuk menyiapkan roll $\mathrm{j}$.

$\mathrm{Xj}$ : jumlah steel billet yang diproses melalui roll $\mathrm{j}$.

$\mathrm{T}$ : waktu yang tersedia (detik/minggu).

\section{c. Batasan Permintaan}

Proses pembuatan steel billet menjadi besi beton sesuai dengan permintaan (made to order). Dalam memenuhi permintaan dari pelanggan, PT. X menetapkan kebijakan bahwa permintaan yang dikerjakan adalah permintaan yang dikumpulkan 1 minggu sebelumnya. Penulisan pemodelan untuk batasan permintaan sebagai berikut:

$$
\sum_{i \in I} s Y_{i}+M_{k}-L_{k}=D_{k}, \mathrm{k}=1,2, \ldots . ., \mathrm{p}
$$

Keterangan:

$\mathrm{s}$ : berat steel billet, ton.

Dk : permintaan perminggu, ton.

Persamaan di atas terlihat bahwa selain batasan permintaan, terdapat juga batasan lain yang diperlukan yaitu: M (kekurangan produk) dan L (kelebihan produk). Kelebihan dan kekurangan produk ini tidak diinginkan oleh perusahaan karena dapat menyebabkan terjadinya kerugian. Agar perusahaan tidak mengalami kerugian terlalu besar, maka kekurangan dan kelebihan produk harus dibatasi. Hal tersebut dilakukan supaya produk yang mendapat keuntungan kecil juga dibuat sehingga tidak hanya produk yang keuntungan besar saja yang dibuat. Model batasan M dan L sebagai berikut:

$$
\begin{array}{ll}
M_{k} \leq B M_{k} & , \mathrm{k}=1,2, \ldots . ., \mathrm{p} \\
L_{k} \leq B L_{k} & , \mathrm{k}=1,2, \ldots . ., \mathrm{p}
\end{array}
$$

Keterangan:

BMk : batas kekurangan produk, ton.

BLk : batas kelebihan produk, ton. 


\section{d. Batasan Jumlah Steel Billet Perminggu}

Keterbatasan steel billet yang ada membatasi jumlah steel billet yang bisa diproduksi oleh perusahaan. Batasan ini berguna untuk menentukan prioritas pengerjaan produk. Produk yang mempunyai keuntungan besar akan diproduksi lebih dulu, sedangkan produk yang mempunyai keuntungan paling kecil akan dibuat jika steel billet masih ada. Jumlah steel billet perminggu (SW) terletak di awal produksi, yaitu steel billet yang diproses menjadi besi beton yang keluar dari roll 1. Batasan jumlah steel billet perminggu ini dapat dirumuskan sebagai berikut:

$$
X_{1} \leq S W
$$

Keterangan:

SW : jumlah steel billet perminggu, ton.

\section{e. Batasan Switching}

Batasan switching ini berguna untuk menjamin apabila steel billet diproses melalui sebuah roll, maka roll tersebut harus diaktifkan. Penulisan pemodelan untuk batasan switching sebagai berikut:

$$
X_{j}-\varepsilon \times R_{j} \leq 0 \quad, \quad \mathrm{j}=1,2, \ldots . . \mathrm{n}
$$

Keterangan:

$\varepsilon$ : sebuah nilai yang harganya lebih besar dari jumlah steel billet yang tersedia perminggu.

\section{HASIL DAN PEMBAHASAN}

\section{Penerapan Model}

Penerapan model matematis untuk mendapatkan keuntungan maksimal akan diujikan di bagian produksi yaitu di rolling mill 1 pada PT. X. Besi beton yang akan digunakan pada penelitian ini hanya yang berdiameter $6 \mathrm{~mm}$ sampai dengan $14 \mathrm{~mm}$. Untuk diameter $15 \mathrm{~mm}$ sampai dengan $32 \mathrm{~mm}$ yang diproduksi di rolling mill 2 tidak dibahas pada penelitian ini.

Keuntungan (laba) yang diperoleh pada penjualan besi beton didapat dari harga jual besi beton dikurangi dengan biaya pembuatan steel billet, biaya enegi dan biaya lain-lain yang dibutuhkan untuk mendukung jalannya proses produksi.

\begin{tabular}{|c|c|c|c|c|c|c|}
\hline \multirow[b]{2}{*}{$\begin{array}{l}\text { Diameter } \\
\text { Besi Beton }\end{array}$} & \multirow{2}{*}{$\begin{array}{c}\text { Harga Jual } \\
\text { Besi Beton } \\
\text { (Perkilogram) }\end{array}$} & \multirow{2}{*}{$\begin{array}{c}\text { Biaya } \\
\text { Pembuatan } \\
\text { Steel Billet } \\
\text { (Perkilogram) }\end{array}$} & \multicolumn{2}{|c|}{ Biaya Proses Produksi } & \multirow[b]{2}{*}{$\begin{array}{c}\text { Laba } \\
(1 \mathrm{Kg})\end{array}$} & \multirow[b]{2}{*}{$\begin{array}{c}\text { Laba } \\
(600 \mathrm{Kg})\end{array}$} \\
\hline & & & $\begin{array}{l}\text { Biaya } \\
\text { Energi }\end{array}$ & $\begin{array}{c}\text { Biaya } \\
\text { Lain-lain }\end{array}$ & & \\
\hline 6 & 16,771 & 13,310 & 503 & 1,677 & 1,281 & 768,510 \\
\hline 7 & 22,827 & 18,116 & 685 & 2,283 & 1,743 & $1,045,926$ \\
\hline 8 & 29,814 & 23,662 & 894 & 2,981 & 2,276 & $1,365,643$ \\
\hline 9 & 37,734 & 29,947 & 1,132 & 3,773 & 2,881 & $1,728,756$ \\
\hline 10 & 46,585 & 36,972 & 1,398 & 4,659 & 3,557 & $2,134,170$ \\
\hline 11 & 56,368 & 44,736 & 1,691 & 5,637 & 4,304 & $2,582,424$ \\
\hline 12 & 67,082 & 53,240 & 2,012 & 6,708 & 5,122 & $3,072,996$ \\
\hline 13 & 78,729 & 62,483 & 2,362 & 7,873 & 6,012 & $3,606,930$ \\
\hline
\end{tabular}

Tabel 1. Keuntungan Penjualan Besi Beton (Rp./steel billet) 


\begin{tabular}{|c|c|c|c|c|c|c|}
\hline \multirow[b]{2}{*}{$\begin{array}{l}\text { Diameter } \\
\text { Besi Beton }\end{array}$} & \multirow[b]{2}{*}{$\begin{array}{c}\text { Harga Jual } \\
\text { Besi Beton } \\
\text { (Perkilogram) }\end{array}$} & \multirow{2}{*}{$\begin{array}{c}\text { Biaya } \\
\text { Pembuatan } \\
\text { Steel Billet } \\
\text { (Perkilogram) }\end{array}$} & \multicolumn{2}{|c|}{ Biaya Proses Produksi } & \multirow[b]{2}{*}{$\begin{array}{l}\text { Laba } \\
(1 \mathrm{Kg})\end{array}$} & \multirow[b]{2}{*}{$\begin{array}{c}\text { Laba } \\
(600 \mathrm{Kg})\end{array}$} \\
\hline & & & $\begin{array}{c}\text { Biaya } \\
\text { Energi }\end{array}$ & $\begin{array}{c}\text { Biaya } \\
\text { Lain-lain }\end{array}$ & & \\
\hline 14 & 91,307 & 72,465 & 2,739 & 9,131 & 6,972 & $4,183,182$ \\
\hline
\end{tabular}

Keseluruhan data yang diperoleh akan diformulasikan dan diselesaikan menggunakan model pemrograman linier dengan bantuan software Lingo. Langkah-langkah yang dilakukan untuk formulasi problem adalah sebagai berikut:

\section{Variabel Keputusan}

Pada penelitian ini, variabel keputusannya adalah:

$\mathrm{Y}_{\mathrm{i}}$ : jumlah steel billet (dalam satuan batangan) yang diproses (melalui roll i) menjadi besi beton dengan bermacam-macam diameter.

Tabel 2. Variabel Y (Steel Billet) yang menjadi Besi Beton

\begin{tabular}{|c|c|c|c|c|c|}
\hline $\begin{array}{l}\text { Diameter } \\
\text { Besi Beton }\end{array}$ & $\begin{array}{l}\text { Melalui } \\
\text { Roll }\end{array}$ & $\begin{array}{c}\begin{array}{c}\text { Steel Billet } \\
\text { menjadi Besi } \\
\text { Beton }\end{array} \\
\end{array}$ & $\begin{array}{l}\text { Diameter } \\
\text { Besi Beton }\end{array}$ & $\begin{array}{l}\text { Melalui } \\
\text { Roll }\end{array}$ & $\begin{array}{c}\text { Steel Billet } \\
\text { menjadi Besi } \\
\text { Beton }\end{array}$ \\
\hline 14 & 89 & Y1 & \multirow{10}{*}{7} & 132 & Y45 \\
\hline 13 & 90 & Y2 & & 133 & Y46 \\
\hline 12 & 91 & Y3 & & 134 & Y47 \\
\hline 12 & 92 & $\mathrm{Y} 4$ & & 136 & Y48 \\
\hline \multirow{3}{*}{1} & 93 & Y5 & & 137 & Y49 \\
\hline & 94 & Y6 & & 138 & Y50 \\
\hline & 96 & Y7 & & 139 & Y51 \\
\hline \multirow{5}{*}{10} & 95 & Y8 & & 140 & Y52 \\
\hline & 97 & Y9 & & 141 & Y53 \\
\hline & 98 & $\mathrm{Y} 10$ & & 142 & Y54 \\
\hline & 100 & Y11 & \multirow{23}{*}{6} & 29 & Y55 \\
\hline & 104 & Y12 & & 37 & Y56 \\
\hline \multirow{8}{*}{9} & 99 & Y13 & & 43 & Y57 \\
\hline & 101 & Y14 & & 45 & Y58 \\
\hline & 103 & Y15 & & 46 & Y59 \\
\hline & 105 & Y16 & & 50 & Y60 \\
\hline & 107 & Y17 & & 52 & Y61 \\
\hline & 108 & Y18 & & 53 & Y62 \\
\hline & 109 & Y19 & & 54 & Y63 \\
\hline & 110 & Y20 & & 56 & Y64 \\
\hline \multirow{13}{*}{8} & 102 & Y21 & & 57 & Y65 \\
\hline & 106 & Y22 & & 61 & Y66 \\
\hline & 111 & Y23 & & 63 & Y67 \\
\hline & 112 & Y24 & & 64 & Y68 \\
\hline & 114 & Y25 & & 65 & Y69 \\
\hline & 115 & Y26 & & 67 & Y70 \\
\hline & 118 & Y27 & & 68 & Y71 \\
\hline & 120 & Y28 & & 70 & Y72 \\
\hline & 121 & Y29 & & 71 & Y73 \\
\hline & 124 & Y30 & & 72 & Y74 \\
\hline & 126 & Y31 & & 73 & Y75 \\
\hline & 130 & Y32 & & 75 & Y76 \\
\hline & 135 & Y33 & & 76 & Y77 \\
\hline
\end{tabular}




\begin{tabular}{|c|c|c|c|c|c|}
\hline $\begin{array}{c}\text { Diameter } \\
\text { Besi Beton }\end{array}$ & $\begin{array}{l}\text { Melalui } \\
\text { Roll }\end{array}$ & $\begin{array}{c}\text { Steel Billet } \\
\text { menjadi Besi } \\
\text { Beton }\end{array}$ & $\begin{array}{c}\text { Diameter } \\
\text { Besi Beton }\end{array}$ & $\begin{array}{c}\text { Melalui } \\
\text { Roll }\end{array}$ & $\begin{array}{c}\text { Steel Billet } \\
\text { menjadi Besi } \\
\text { Beton }\end{array}$ \\
\hline \multirow{11}{*}{7} & 113 & Y34 & & 77 & Y78 \\
\hline & 116 & Y35 & & 78 & Y79 \\
\hline & 117 & Y36 & & 79 & Y80 \\
\hline & 119 & Y37 & & 81 & Y81 \\
\hline & 122 & Y38 & & 82 & Y82 \\
\hline & 123 & Y39 & & 83 & Y83 \\
\hline & 125 & Y40 & & 84 & Y84 \\
\hline & 127 & Y41 & & 85 & Y85 \\
\hline & 128 & Y42 & & 86 & Y86 \\
\hline & 129 & Y43 & & 87 & Y87 \\
\hline & 131 & Y44 & & 88 & Y88 \\
\hline
\end{tabular}

\section{Fungsi Tujuan}

Fungsi tujuan dapat dirumuskan sebagai berikut:

$$
\begin{aligned}
& \operatorname{Max} \mathrm{Z}=4183 * \mathrm{Y}_{1}+3607 * \mathrm{Y}_{2}+\ldots . .-\left(1281 * \mathrm{M}_{6}+64 * \mathrm{~L}_{6}+\ldots . .+6972 * \mathrm{M}_{14}+\right. \\
& \left.348 * \mathrm{~L}_{14}\right) \\
& -\left(31 * \mathrm{R}_{1}+\ldots .+53 * \mathrm{R}_{88}\right)
\end{aligned}
$$

\section{Fungsi Pembatas:}

Fungsi pembatas yang membatasi fungsi tujuan pada penelitian ini adalah:

a. Batasan Input-Output

$$
\begin{array}{ll}
X_{2}+X_{3}+X_{89} & <X_{1} \\
X_{4}+X_{5}+X_{90} & <X_{2} \\
\cdot & \\
\cdot & \\
X_{88}+X_{142} & <X_{80}
\end{array}
$$

b. Batasan Waktu

$$
63 * \mathrm{X}_{1}+\ldots . .+7 * \mathrm{X}_{88}+19 * \mathrm{R}_{1}+\ldots . .+61 * \mathrm{R}_{88}<7 * 24 * 60 * 60
$$

c. Batasan Permintaan, Kekurangan Permintaan dan Kelebihan Permintaan

- Permintaan ukuran 14:

$$
\begin{gathered}
0,6 * \mathrm{Y}_{1}+\mathrm{M}_{14}-\mathrm{L}_{14}=250 \\
\mathrm{M}_{14}<1,25 \\
\mathrm{~L}_{14}<1,25
\end{gathered}
$$

- Permintaan ukuran 13:

$$
\begin{gathered}
0,6 * Y_{2}+M_{13}-L_{13}=750 \\
M_{13}<3,75 \\
L_{13}<3,75
\end{gathered}
$$

- Permintaan ukuran 6:

$$
\begin{aligned}
& 0,6 * \mathrm{Y}_{55}+\ldots . .+0,6 * \mathrm{Y}_{88}+\mathrm{M}_{6}-\mathrm{L}_{6}=75 \\
& \mathrm{M}_{6}<0,375 \\
& \mathrm{~L}_{6}<0,375
\end{aligned}
$$


d. Batasan Jumlah Steel Billet Perminggu

$$
\mathrm{X}_{1}<4667
$$

e. Batasan Switching

$$
\begin{aligned}
& \mathrm{X}_{1}-5000 * \mathrm{R}_{1}<0 \\
& \mathrm{X}_{2}-5000 * \mathrm{R}_{2}<0 \\
& . \\
& . \\
& \mathrm{X}_{99}-5000 * \mathrm{R}_{99}<0
\end{aligned}
$$

Hasil pengolahan data tersebut menunjukkan bahwa keuntungan maksimal perusahaan selama seminggu yang semula rata-rata Rp. 10.000.000.000,- menjadi sebesar Rp. 12.314.360.000,- dengan jumlah iterasi sebanyak 5015 kali. Dengan kata lain perusahaan selama seminggu dapat memperoleh keuntungan maksimal 23,14\% lebih besar dari keuntungan yang diperoleh sebelumnya.

Jumlah steel billet yang diproses menjadi besi beton di PT. X untuk memenuhi permintaan selama seminggu yaitu sebanyak 4.658,96 batang steel billet. Perincian untuk masing-masing diameter yang diperoleh pada penelitian ini adalah sebagai berikut:
a. Diameter $14=416,67$ steel billet.
b. Diameter $13=1250$ steel billet.
c. Diameter $12=416,67$ steel billet.
d. Diameter $11=200$ steel billet.
e. Diameter $10=1250$ steel billet.
f. Diameter $9=183,33$ steel billet.
g. Diameter $8=625$ steel billet.
h. Diameter $7=191,67$ steel billet.
i. Diameter $6=125,63$ steel billet.

Secara detail dapat ditunjukkan pada Gambar 3.

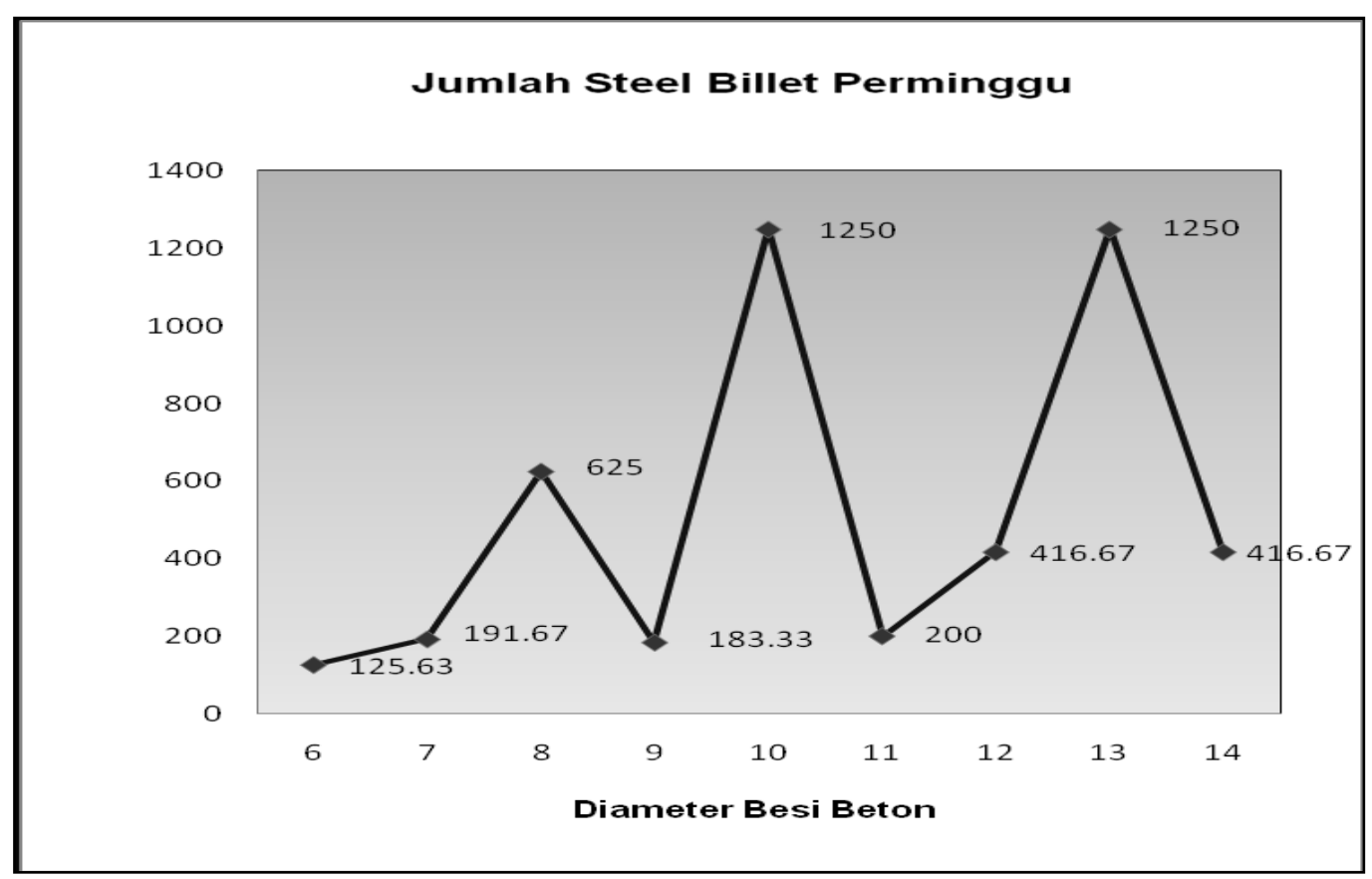

Gambar 3. Permintaan Selama Seminggu (steel billet/minggu) 
Dengan demikian jumlah steel billet yang tersedia dalam waktu seminggu yaitu 4667 batang steel billet bisa mencukupi semua ukuran diameter sesuai dengan permintaan. Sedangkan sisa steel billet sebanyak 8,01 batang yang telah diproses menjadi besi beton itu merupakan kelebihan produk. Kelebihan produk tersebut terjadi pada ukuran diameter 6 .

\section{KESIMPULAN DAN SARAN}

Berdasarkan hasil pengolahan data dan analisa yang telah dilakukan, maka kesimpulan penelitian ini adalah: dengan menggunakan metode pemrograman linier keuntungan maksimal yang diperoleh perusahaan selama seminggu meningkat sebesar 2.314.360.000,dari Rp. 10.000.000.000,- menjadi Rp. 12.314.360.000,-. Jadi, setelah dilakukan optimasi menggunakan pemrograman linier, peningkatan persentase keuntungan yang diperoleh perusahaan ini sebesar 23,14\%. Perusahaan bisa memproduksi besi beton untuk semua diameter sesuai dengan permintaan, dan hanya sedikit kelebihan produk yang terjadi yaitu pada besi beton berdiameter 6 .

Dari pembahasan dan kesimpulan yang telah dijelaskan di atas, maka dapat disarankan hal-hal sebagai berikut: perusahaan hendaknya menggunakan metode pemrograman linier sebagai panduan penyusunan produksi dalam melakukan kegiatan pada minggu-minggu berikutnya di rolling mill 1 . Selain itu, model matematis dalam penelitian ini perlu dikembangkan dengan mempertimbangkan variabel selain permintaan perminggu, kekurangan produk, kelebihan produk, dan roll sehingga model matematis menjadi lebih baik dalam mengoptimalkan rencana produksi.

\section{DAFTAR PUSTAKA}

[1] Daft, L.D. 2007. Manajemen. Jilid 1, Edisi 6: Terjemahan. Salemba Empat, Jakarta.

[2] Soekartawi. 2003. Teori Ekonomi Produksi dengan Pokok Bahasan Analisis Fungsi Cobb-Douglas. PT. Rajawali Pers, Jakarta.

[3] Pratama, D.S. 2012. Optimalisasi Produksi Industri Sambal Menggunakan Pemrograman Linier. E-Jurnal Teknologi Industri, Universitas Gunadarma.

[4] Partono, Windu. 2007. Evaluasi Kelayakan Pendanaan Proyek dengan Teknik Pemrograman Linier. Jurnal Teknik Sipil Vol. 28 No.1. 2007 Hal 1-8.

[5] Asmundsson, J., Uzsoy, R., dan Rardin, RL. 2002. An Alternative Modeling Framework for Aggregate Production Planning. Research Report, Laboratory for Extended Enterprises at Purdue, Purdue university, West Lafayette, In 47907-1287.

[6] Gitosudarmo, Indriyo. 2002. Manajemen Operasi, Edisi Kedua. BPFE, Yogyakarta.

[7] Andrie, Y. 2012. Penerapan Model Linear Programming Untuk Mengoptimalkan Jumlah Produksi Dalam Memperoleh Keuntungan Maksimal CV. Makmur Berseri. Tesis. Universitas Binus, Jakarta.

[8] Heizer, Jay dan Render, Barry. 2005. Operations Managament. Salemba Empat, Jakarta.

[9] Mulyono, Sri. 2007. Riset Operasi, Edisi Revisi. Lembaga Penerbit Fakultas Universitas Indonesia, Jakarta. 